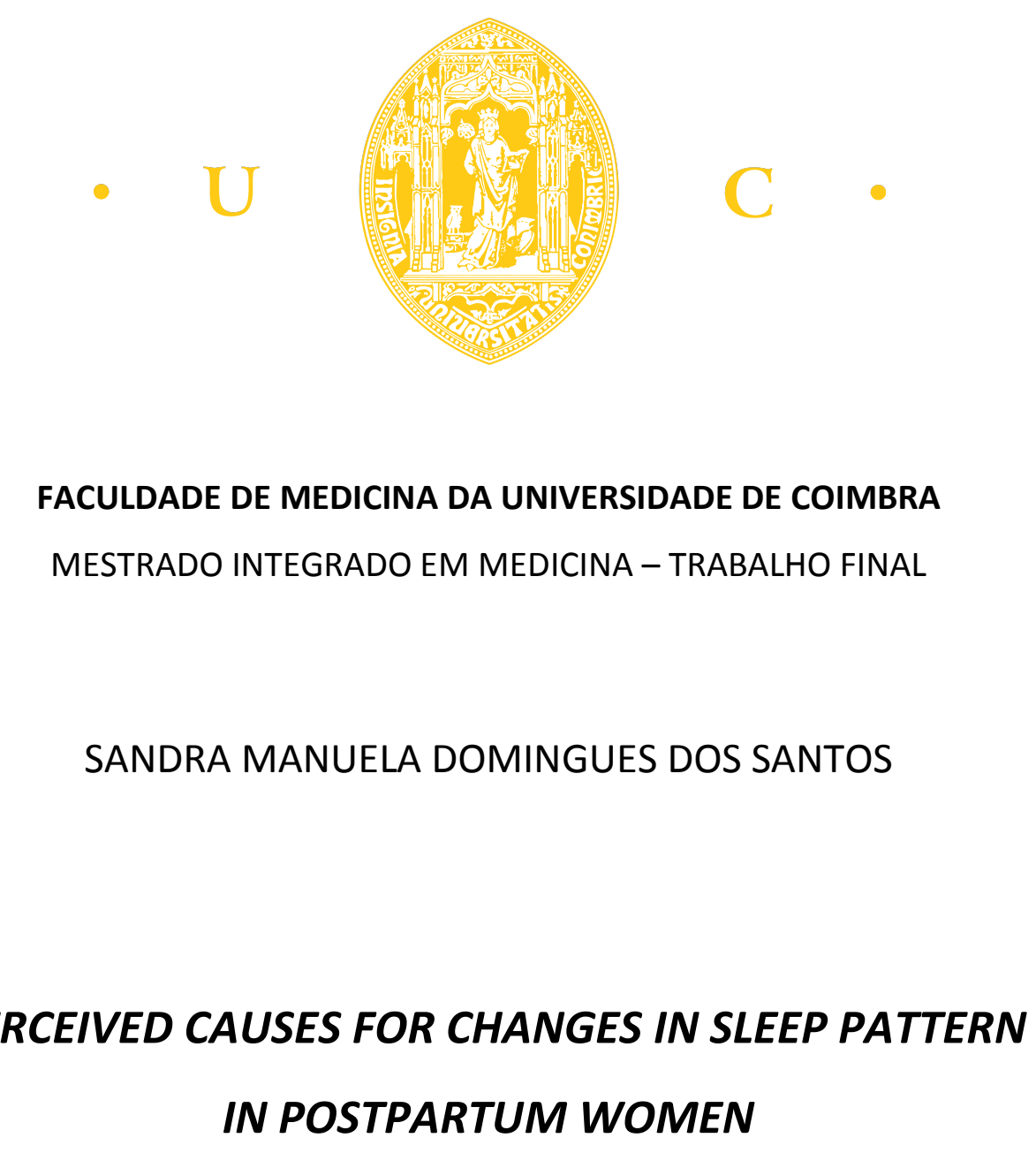

\title{
PERCEIVED CAUSES FOR CHANGES IN SLEEP PATTERN IN POSTPARTUM WOMEN
}

\author{
ARTIGO CIENTÍFICO \\ ÁREA CIENTÍFICA DE PSICOLOGIA MÉDICA \\ Trabalho realizado sob a orientação de: \\ DOUTORA ANA TELMA PEREIRA
}

MARÇO/2016 



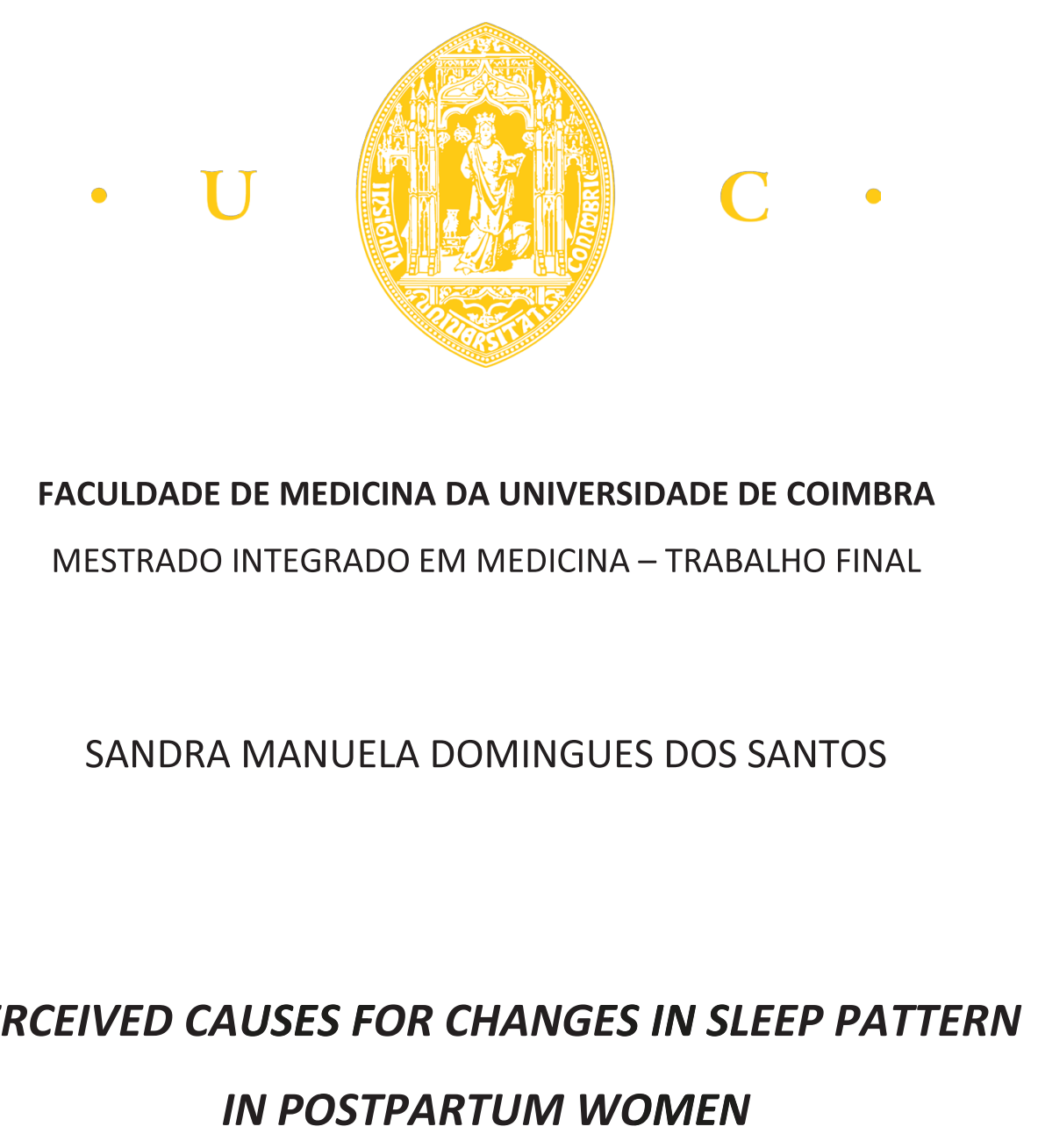

\title{
PERCEIVED CAUSES FOR CHANGES IN SLEEP PATTERN IN POSTPARTUM WOMEN
}

\author{
ARTIGO CIENTÍFICO \\ ÁREA CIENTÍFICA DE PSICOLOGIA MÉDICA \\ Trabalho realizado sob a orientação de: \\ DOUTORA ANA TELMA PEREIRA
}

MARÇO/2016 
Faculty of Medicine

University of Coimbra

\section{PERCEIVED CAUSES FOR CHANGES IN SLEEP PATTERN \\ IN POSTPARTUM WOMEN}

Sandra Manuela Domingues dos Santos

*email of the author: smdsantos@gmail.com 


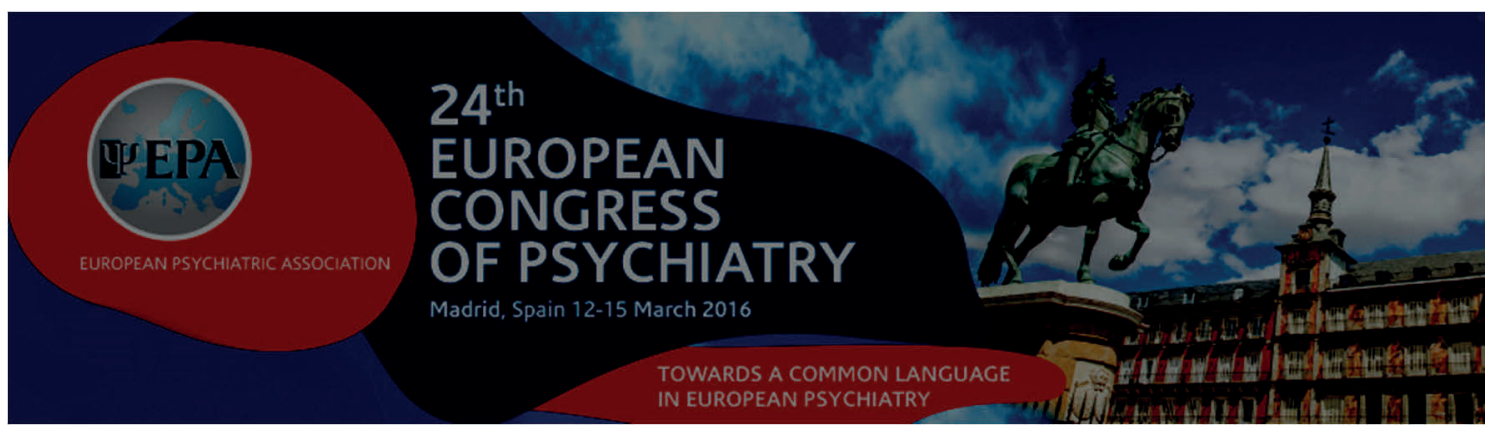

Part of this work was presented as a poster at the $24^{\text {th }}$ European Congress of Psychiatry (EPA 2016), Madrid, Spain, 12-15 March 2016.

\section{Reference:}

Sandra Santos, Ana Telma Pereira, Maria João Soares, Mariana Marques, António Macedo (2016). Perceived causes for changes in sleep pattern in postpartum women. European Psychiatry (in press). 
TABLE OF CONTENTS

Abbreviations

Resumo

3

Abstract

5

1. INTRODUCTION

7

2. METHODS

9

3. RESULTS

4. DISCUSSION

22

5. ACKNOWLEDGEMENTS

26

6. REFERENCES 


\section{ABBREVIATIONS}

PDSS - Postpartum Depression Screening Scale

POMS - Profile of Mood States

BDI-II - Beck Depression Inventory-II

DIGS - Diagnostic Interview for Genetic Studies

OPCRIT - Operational Criteria Checklist for Psychotic Illness

DITQ - Difficult Infant Temperament Questionnaire

ICD-10 - International Classification of Diseases Tenth Edition

DSM-IV - Diagnostic and Statistical Manual of Mental Disorders Fourth Edition SOP - Self Oriented Perfectionism

SPP - Socially prescribed Perfectionism

Md - Median

SD - Standard Deviation

OR - Odds Ratio 


\section{RESUMO}

Introdução: Mulheres no pós-parto sofrem mudanças significativas no padrão de sono devido a uma série de razões (anatómicas, hormonais, cuidados com o bebé, etc.) e sabe-se que a insónia e depressão estão associadas, mas não há estudos que explorem as causas percebidas pelas mulheres para as alterações no seu padrão de sono durante esse período. Assim, o objetivo deste trabalho é investigar as causas que mulheres no pós-parto atribuem às suas mudanças no padrão de sono e analisar as suas associações com variáveis obstétricas, do sono, dos estados de humor e dos sintomas depressivos.

Métodos: Três meses após o parto, 192 mulheres responderam a um inquérito contendo variáveis obstétricas, do sono, da saúde, da Escala de Depressão Pós-Parto (PDSS ${ }^{1}$ ) e do Perfil de Estados de Humor (POMS). No caso de as mulheres terem respondido positivamente à questão sobre se tiveram alterações do padrão de sono desde o nascimento do bebé, foi-lhes pedido que identificassem a(s) causa(s) possíveis, com base numa questão de escolha múltipla. Testes de Qui quadrado e de $T$ de Student (ou equivalentes não-paramétricos) foram aplicados conforme apropriado.

Resultados: $64.6 \%$ das mulheres referiram-se a alguma(s) causa(s); as mais citadas foram alimentação / cuidado do bebé e crianças mais velhas (32.3\%) e as preocupações (com o bebé e com problemas da vida) (29.5\%). Ao longo do estudo, consideramos dois grupos: o "grupo das preocupações" e o "grupo das outras causas". No que diz respeito às variáveis obstétricas, observou-se uma relação positiva entre o grupo preocupações e parto instrumental vs. vaginal ou vs. cesariana; além disso, mulheres que estavam a amamentar em exclusivo referiram as preocupações em mais elevada proporção do que as mulheres que estavam a usar biberão. Não foram observadas diferenças significativas entre os dois grupos quando se consideram as variáveis relacionadas com o stresse percebido no pós-parto, apoio social, qualidade de vida, saúde no passado ou problemas de saúde no pós-parto, temperamento da criança ou perfeccionismo. Ao nível dos sintomas e afectos depressivos, as mulheres no "grupo das preocupações" tiveram pontuações mais altas no POMS Depressão e Fadiga-Inércia, no BDI-II total, na dimensão somática-ansiedade (do BDI-II) e na maioria das dimensões sintomáticas do PDSS (Distúrbios do apetite e do sono, Ansiedade/insegurança, Confusão mental, Perda do self, Culpa/vergonha, Desrealização e fracasso, Dificuldades de concentração, Labilidade emocional e Dificuldades em dormir). 
Conclusão: É importante distinguir as causas de alterações no padrão do sono em mulheres no pós-parto. As preocupações como uma causa percebida para a alteração do padrão de sono no pós-parto parecem ter um impacto e significado clínico maiores do que causas relacionadas com as necessidades do bebé, pelo que especial atenção deve ser prestada pelos profissionais de saúde para com as mulheres que se referem a esta causa específica para não dormir.

Palavras-chave: Pós-parto, Causas para não dormir, preocupações, insónia, depressão. 


\section{ABSTRACT}

Introduction: Women at postpartum suffer significant changes in sleep pattern due to a number of reasons (anatomical, hormonal, baby care demands, etc.) and it is known that insomnia and depression are associated, but no studies have explored the causes women perceive for the alterations in their sleep pattern during that period.

The aim of this work is to investigate the causes that postpartum women most mention for changes in sleep pattern and its associations with obstetric and sleep variables and with mood states and depressive symptoms.

Methods: At three months postpartum 192 women fill in a booklet containing obstetric and sleep variables, the Postpartum Depression Screening Scale (PDSS ${ }^{1}$ ) and the Profile of Mood States (POMS). If they experienced changes in their sleep pattern, they were asked about the perceived cause(s) (multiple choice). Qui Square and Student T tests were applied as appropriate.

Results: $64.6 \%$ Women referred to some cause(s); the most mentioned were feeding/baby care and older children care (32.3\%) and worries (baby and life problems related) (29.5\%). Throughout the study we considered two groups: the "worries group" and the "other causes group". Concerning the obstetric variable, we observed a positive relation between the worries group and assisted delivery vs. vaginal or vs. caesarean-section; in addition, women exclusively breastfeeding reported worries in higher proportions than women bottle-feeding. No significant differences were observed between the two groups when considering the variables related with perceived stress postpartum, perceived social support, quality of life, past health or health problems at the postpartum, infant temperament or perfectionism. At the level of the depressive symptoms, women in the "worries group" had higher scores in POMS Depression and Fatigue-Inertia, BDI-II total and somatic-anxiety dimension and most of the symptomatic dimensions of PDSS (Sleep and eating disturbances, Anxiety/insecurity, Mental confusion, Loss of self, Guilty/shame, Derealization-failure, Concentration difficulties and Emotional lability as well as Sleeping difficulties).

Conclusion: It is important to distinguish the causes for changes in sleep pattern in postpartum women. Worries as a perceived cause have a higher impact and clinical significance than causes related to baby care demands and special attention should be 
paid by healthcare professional to women referring to this specific cause to sleep pattern in the postpartum.

Key-words: Postpartum, perceived causes to sleep difficulties, worry, insomnia, depression. 


\section{INTRODUCTION}

Insomnia, one of the most prevalent health problems in the general population worldwide $^{2}$, can be caused by psychiatric and medical conditions, unhealthy sleep habits, specific substances, and/or certain biological factors. According to the International Classification of Sleep Disorders - Second Edition ${ }^{3}$, it may be defined as both a symptom and a disorder.

Being a symptom, it implies one or more of the following: difficulty initiating or maintaining sleep, waking from sleep too early, and/or the complaint of nonrestorative sleep. As a disorder/syndrome (primary insomnia), these sleep difficulties must occur in association with a complaint of impaired daytime functioning (e.g. diminished vocational functioning) and in the presence of adequate opportunity to sleep ${ }^{3-5}$. When insomnia arises as a symptom in medical or psychiatric conditions, there is the need for a separate diagnosis and the sleep problem is considered a secondary insomnia ${ }^{3-5}$. Several studies have showed an association between insomnia and high levels of depression. This pattern is found when considering only the presence of depressive symptomatology $\mathrm{y}^{6-11}$ as well as when a clinical diagnosis is present, either on longitudinal or cross-sectional studies ${ }^{12-19}$. The relationship between insomnia and depression is bidirectional, since insomnia is frequently reported in depressed patients ${ }^{20}$, but it can also be viewed as an independent risk factor for developing depression ${ }^{21,22}$.

Pregnancy has been recognized as a period of major physiological physic and psychological changes ${ }^{23}$, which can be viewed as a stressful event ${ }^{24}$. An elevated percentage of women $(84 \%)$ reveals one or more symptoms of insomnia during the several weeks of pregnancy, with $30 \%$ of them referring to have rarely a good night of sleep during the entire pregnancy ${ }^{25}$. In postpartum period, the sleep pattern of the mother suffers significant changes due to a sudden decrease in the hormone levels associated with placenta function and also as a result of the irregular sleep pattern of the newborn. These factors contribute to decrease the quality of sleep and interfere with the sleep-wake rhythm of the mothers, causing daytime sleepiness and fatigue. Sleep disturbances are also frequent in the 1 st month postpartum ${ }^{26}$. The total sleep duration decreases from the first trimester of pregnancy until one month postpartum and sleep efficiency is lower in the three months postpartum compared to pregnancy. Women who reported significant sleep deprivation and whose babies have trouble sleeping, can be at greater risk of suffering from depression ${ }^{27}$. It should, however, be 
noted that there are other factors that can influence sleep in the postpartum; for example, mother's age, the type of delivery, the type of infant feeding, the difficult infant temperament, the return to work, the number of children at home and availability of the partner or other family members for help during night ${ }^{27}$.

Changes of sleep during postpartum, as well as insomnia experience increase a woman's likelihood of suffering depressive symptoms / postpartum depression and constitute an important correlation of depressive symptoms in pregnancy ${ }^{28}$, therefore this is a particularly good period to investigate the causes that postpartum women most mention for changes in sleep pattern and correlate them with obstetric and sleep variables and depressive symptoms. Although our main focus were the women perceived causes for postpartum sleep pattern changes, we also considered some of the most well established risk factors for postpartum depression/depressive symptomatology: lifetime history of depression and the presence of depressive/anxious symptomatology in pregnancy. 


\section{METHODS}

The present work comes from a wider research project "Postpartum Depression and Sleep" (FCT, POCI/SAU-ESP/57068), approved by the Ethic Committee of the Faculty of Medicine, Coimbra.

\subsection{Procedures}

Women with uncomplicated pregnancies, 18 years old or more, at three month postpartum were approached while waiting for their medical appointment at local health medical centres, local maternities and childbirth preparation classes and invited to participate in the study. Aims and procedures were explained, confidentiality was assured and written consent was obtained. Participants fill in a booklet containing obstetric and sleep variables and the Postpartum Depression Screening Scale $\left(\mathrm{PDSS}^{1}\right.$ ). If they experienced changes in their sleep pattern, they were asked about the perceived cause(s) (multiple choice), including demographic, obstetric and psychological characteristics, such as insomnia, stress perception and support, perceived health, quality of life, affection, baby temperament and personality, current mood and depressive symptomatology (e.g. Postpartum Depression Screening Scale and Profile of Mood States, explained in another section). The recruitment of a sample from the general population had the aim of avoiding the selection of subgroups with high-risk pregnancies (followed in obstetric units). All the women were interviewed by trained clinical psychologists with the Diagnostic Interview for Genetic Studies (DIGS ${ }^{29}$ ). This instrument and the Portuguese version of the OPerational CRITeria Checklist for Psychotic Illness (OPCRIT ${ }^{30}$ ) were used to obtain the psychiatric diagnosis according to ICD-10 4 and DSM-IV 5 criteria.

\subsection{Sample}

Our sample comprised a total of 192 three month postpartum women with a mean age of 31.1 years $(S D=4.17$; range=18-40; Mean baby age=12.39 weeks; $S D=.957$; Range $=11-15)$ at the moment of the interview. The majority of women was married (85.4\%), 27\% were living with a partner and $0.5 \%$ were single/never married. $53.1 \%$ were primiparae and $46.9 \%$ multiparae. Most of the sample included women with a low to middle educational level (66.9\%).

The educational level variable was categorized the following way: low educational level (primary+elementary); medium educational level (high school) and high educational level (higher education). Approximately $8.9 \%$ of women were working, $76.6 \%$ were on 
medical leave and $12 \%$ were unemployed. Regarding the type of delivery, $42.2 \%$ had a normal delivery, $40.1 \% \%$ had a caesarean and $17.7 \%$ had an instrumental birth. Most mothers were breast feeding (55.2\%), 28.1\% were bottle feeding and $16.7 \%$ were mixed feeding. Concerning depression diagnosis, Major Depression (DSM-IV) prevalence was of $5.7 \%$; Depression (ICD-10) prevalence was of $6.3 \%$.

\subsection{Variables, Measures and Instruments}

\section{3.1. Sociodemographic variables}

The booklet (as well as at the DIGS) included questions assessing age, nationality, marital status, educational level, work status (working, unemployed and at leave) and parity (primiparas or multiparas).

\subsubsection{Social Variables}

\subsubsection{Stress perception/life stress events}

This variable was assessed with the question "how stressful is your life at the present moment? (e.g. problems and worries about life, at home, at work, with family, neighbours, friends, economic problems, disease, death and/or others" (not at all stressful vs. a little bit stressful vs. very stressful). Those who reported their life as not at all/not much stressful were categorized as having low perceived stress levels vs. those reporting their life as a little bit stressful/ very stressful (categorized as having high perceived stress levels).

\subsubsection{Perceived social support}

This variable was evaluated with the question "do you feel that, in general, you have the support and help you need (from your husband/partner, family, friends, neighbours and/or others)?". Women answering always/often were categorized as having high social support; women answering rarely/almost never were categorized as having low social support.

\subsubsection{Quality of life}

This variable was evaluated with the question "in general how do you rate your quality of life at this moment?" - very good, good, neither good or bad, bad, very bad. 


\subsubsection{Health perception}

This variable was evaluated with the question "In general how has been your health" very good/good vs. neither good or bad/bad/very bad.

\subsubsection{Health problem or complication postpartum}

This variable was evaluated with the question "Have you have any complications or health problem after birth that led you to seek medical help? - No vs. Medical problems (minor + important) vs. Psychiatric problems

\subsection{Obstetric variables}

Type of delivery was categorized as follows: vaginal delivery, caesarean delivery and instrumental delivery (with forceps and/or vacuum extraction). Type of feeding was categorized the following way: 1) breastfeeding; 2) only bottle-feeding and 3) mixed feeding (breastfeeding + bottle-feeding).

\subsection{Sleep/Depression variables}

\subsubsection{Sleep needs}

This variable was evaluated with the following question: "How many hours have you always need of sleep to feel good and function well during the day?" (5 h or less, 5-6 h, 6-7 h, 7-8 h, about 8 h; 8-9 h; 9-10 h, 10 h or more)

\subsubsection{Lifetime history of insomnia}

The survey contained questions assessing lifetime history of insomnia (yes/no): "In your lifetime, have you ever had a period of one month or more when you were sleeping poorly (difficulty falling asleep, waking up many times during the night or waking up too early in the morning and unable to go back to sleep?"). If the answer was "no", the participant was considered a Good Sleeper. Those answering "yes" also to the question: "Did it interfere with your life or activities a lot?" were classified as Insomnia Syndrome Group.

\section{Number of insomnia episodes}




\subsubsection{Current insomnia}

Women were asked to answer five questions about sleep (yes/no), considering the previous month: three regarding insomnia symptoms and two related to insomnia daytime consequences $(\alpha=.77)$. Based on the answers given by the participants three groups were formed: Good Sleepers (without insomnia symptoms and daytime impairment); Insomnia Symptoms Group (with at least one insomnia symptom and without daytime impairment); Insomnia Syndrome Group (with at least one insomnia symptom and sleep related daytime impairment).

2.5.4. Lifetime history of depressive symptoms: assessed with the questions "have you ever had two weeks or more in which you felt discouraged, sad or low, without interest or pleasure?" (yes/no). If the answer was "no", the participant was considered without previous history of depressive symptoms. Those answering "yes" to the question "Did it interfere with your life or activities a lot?" were classified as perception of previous depressive syndrome.

\section{Number of depressive episodes}

\subsection{Postpartum Depression Screening Scale (PDSS ${ }^{1}$ )}

The PDSS is a 35-item self-report instrument that assesses the presence and severity of postpartum depression symptoms and that can be used to screen women with a high probability of meeting depression criteria ${ }^{31}$. Items were developed based on qualitative studies about the subjective experience of postpartum depression (PPD) ${ }^{32}$, reflecting this specific context. It evaluates the subjective experience (thoughts and feelings) of PPD, in seven theoretical dimensions (5 items each: Sleeping/eating disturbances/SLP; anxiety/insecurity/ANX); emotional liability/ELB); mental confusion/MNT; loss of self/LOS; guilt/shame/GLT and suicidal thoughts/SUI) and four empirical factors (Derealization and failure, Concentration difficulties and emotional liability, Suicidal ideation and stigma and Sleeping difficulties). The cut-off score (adjusted to prevalence) for Perinatal Depression (DSM-IV and/or ICD-10) was 66 (Sensitivity 76.0; Specificity 85.3 )

\subsection{Beck Depression Inventory-II}

$\mathrm{BDI}-\|^{32}$ is a self-report instrument, which evaluates the presence and severity of depressive symptoms (in the last 2 weeks). It was developed to accommodate for the changes in DSM-IV (5) major depression criteria. The total score is obtained by summing the 21 items ratings. The maximum total possible score is 63 . The 
Portuguese version of BDI-II has good psychometric characteristics ${ }^{33}$. We used the BDI-II factor structure found for this specific perinatal period ${ }^{34}$, to evaluate the presence and severity of depressive symptoms in two empirical dimensions: Somatic-Anxiety and Cognitive-Affective ${ }^{34}$. The cut-off score (adjusted to prevalence) for Perinatal Depression (DSM-IV and/or ICD-10) was 10 ((Sensitivity 83.3; Specificity 86.1)1).

\subsection{Profile of Mood States}

The Portuguese version ${ }^{35}$ of the Profile of Mood States $\left(\mathrm{POMS}^{36}\right.$ ) is a 65 adjective Likert scale, with each adjective describing feelings and mood states. Following each adjective the subject is required to respond how she has been feeling on a 5 point scale which varies from «not at all» (value 0) to «extremely» (value 5), considering the previous month, and not the last week as it was originally requested. The longer the time period defined the more likely personality traits are measured instead of transient mood states $^{36}$. This scale reliably assesses six mood states: Tension-Anxiety (TA), Vigor-Activity (VA), Depression (D), Anger-Hostility (AH), Fatigue (F), ConfusionBewilderment (CB).

\subsection{Difficult Infant Temperament Questionnaire}

Using Difficult Infant Temperament Questionnaire (DITQ ${ }^{37}$ ) to assess mothers' perceptions of their infant's characteristics and behaviour, we evaluated difficult infant temperament, as perceived by mother. A total score of child temperament was calculated by summing the 8 response scores. A high score was associated with a more difficult child temperament (self perceived by the mother).

2.13. Multidimensional Perfectionism Scale ${ }^{38}$ to assess two dimensions: SelfOriented Perfectionism (SOP) and Socially Prescribed Perfectionism (SPP).

\subsection{Statistical analyses}

Statistical analyses were performed using SPSS, version 22, for Windows. Qui Square and Mann-Whitney $U$ tests were applied to compare proportions/means in the variables in relation to perceived causes. 


\section{RESULTS}

Table 1 - Obstetric variables

\begin{tabular}{|l|c|}
\hline Type of delivery & $\mathbf{n ~ ( \% )}$ \\
\hline Vaginal & $81(42.2 \%)$ \\
\hline Caesarean & $77(40.1 \%)$ \\
\hline $\begin{array}{l}\text { Instrumental (forceps and/or vacuum } \\
\text { extraction) }\end{array}$ & $34(17.7 \%)$ \\
\hline \multicolumn{2}{|c|}{} \\
\hline Type of feeding & $106(55.2 \%)$ \\
\hline Breastfeeding & $54(28.1 \%)$ \\
\hline Bottle-feeding & $32(16.7 \%)$ \\
\hline Mixed feeding &
\end{tabular}

As depicted in Table 1, a significant number of women had a vaginal delivery $(n=81$, $42.2 \%)$ but a considerable number underwent caesarean-section ( $n=77,40.1 \%)$ and 34 women $(17.7 \%)$ had an instrumental delivery. Most women $(106,55.2 \%)$ said to be breastfeeding (exclusively), 54 (28.1\%) were bottle-feeding and $32(16.7 \%)$ were in a mixed feeding (breastfeeding + bottle-feeding) system.

Table 2 - Social Variables

\begin{tabular}{|l|c|}
\hline $\begin{array}{l}\text { Stress perception/ life stress } \\
\text { events_PP }\end{array}$ & $\mathbf{n}(\%)$ \\
\hline Low perceived stress levels & $30(15.6 \%)$ \\
\hline High perceived stress levels & $162(84.4 \%)$ \\
\hline \multicolumn{2}{|c|}{} \\
\hline Perceived social support_PP & $189(98.5 \%)$ \\
\hline High perceived social support & $3(1.5 \%)$ \\
\hline Low perceived social support & \\
\hline \multicolumn{2}{|c|}{} \\
\hline Quality of life_PP & $32(16.7 \%)$ \\
\hline very good & $118(61.5 \%)$ \\
\hline Good & $39(20.3 \%)$ \\
\hline Neither good or bad & $3(1.6 \%)$ \\
\hline Bad or very bad & $25(13 \%)$ \\
\hline \multicolumn{2}{|c|}{} \\
\hline Health perception & $167(87 \%)$ \\
\hline Very bad+Bad+neither good or bad & $156(81.3 \%)$ \\
\hline Good+Very good & $34(17.7 \%)$ \\
\hline Health problem or complication_PP & $2(1 \%)$ \\
\hline No & \\
\hline Medical problems (minor + important) & \\
\hline Psychiatric problems &
\end{tabular}


For the social variables at 3 month postpartum (Table 2), most women ( $n=162,84.4 \%$ ) perceived high levels of stress and considered to have a high social support $(n=189$, $98.5 \%$ ). When asked to rate their life quality at that moment, most women considered their life quality good $(n=118,61.5 \%)$, with $16.7 \%$ considering it very good, $20.3 \%$ $(n=39)$ considering it neither good or bad and only $3(1.6 \%)$ considering it very bad or bad.

With regard to variables related to health and, particularly to health problems or complications in the postpartum, most participants did not have any problems $(n=156$, $81.3 \%)$, while $34(17.7 \%)$ women reported having had minor or important medical problems and 2 women (1\%) reported having had psychiatric problems. As for the perception about health in the past, a significant number think that this was good $(n=167,87 \%)$.

\section{Table 3 - Sleep variables}

\begin{tabular}{|l|c|}
\hline Sleep needs & $\mathbf{n ~ ( \% )}$ \\
\hline $5 \mathrm{~h}$ or less & $8(4.2 \% 9$ \\
\hline $5-6 \mathrm{~h}$ & $18(9.4 \%)$ \\
\hline $6-7 \mathrm{~h}$ & $40(20.8 \%)$ \\
\hline $7-8 \mathrm{~h}$ & $53(27.6 \%)$ \\
\hline about 8 h & $44(22.9 \%)$ \\
\hline $8-9 \mathrm{~h}$ & $18(9.4 \%)$ \\
\hline $9-10 \mathrm{~h}$ & $10(5.2 \%)$ \\
\hline \multicolumn{2}{|c|}{} \\
\hline Lifetime insomnia & $133(69.3 \%)$ \\
\hline No & $59(30.7 \%)$ \\
\hline Yes and it afected life or activities & $85(44.3 \%)$ \\
\hline Current Insomnia & $45(23.4 \%)$ \\
\hline Good sleepers & $62(32.3 \%)$ \\
\hline Symptoms Group & \\
\hline Insomnia Syndrome Group & \\
\hline
\end{tabular}

Table 3 presents the sleep variables and shows that most women requires $7 / 8$ hours or about 8 hours of sleep ( $n=53,27.6 \%$ and $n=44,22.9 \%$ ). As for the insomnia, 50 women $(30.7 \%)$ reported having had a month in which they slept poorly. Concerning the current insomnia, most women were classified as Good Sleepers ( $n=85,44.3 \%)$, $45(23.4 \%)$ were included in the Symptoms Group and 62 (32.3\%) were included in the Insomnia Syndrome Group. 
Table 4 - Depression diagnosis

\begin{tabular}{|l|c|}
\hline DSM-IV & $\mathbf{n}(\%)$ \\
\hline Without Major depression & $181(94.3 \%)$ \\
\hline With Major depression & $11(5.7 \%)$ \\
\hline \multicolumn{2}{|c|}{} \\
\hline ICD-10 & $180(93.8 \%)$ \\
\hline Without Depressive disorder & $12(6.3 \%)$ \\
\hline With Depressive disorder &
\end{tabular}

According to the DSM-IV, $11(5.7 \%)$ of the women were diagnosed with Major Depression and according to ICD-10, 12 (6.3\%) women were diagnosed with depression (see table 4).

\section{Frequencies of the causes mentioned for changes in sleep pattern:}

Women were asked whether they had perceived changes in their sleep pattern after childbitrth and $106(57.7 \%)$ answered positively to that question. When women were asked about the causes they perceived for those changes in their sleep pattern, $64.6 \%$ referred to some cause (s), $32.3 \%$ of which mentioned the feeding and/or baby care and older children care and 29.5\% mentioned worries (baby and life problems related). In order to study the associations with demographic, obstetric, sleep, psychosocial and health variables and depressive symptoms, two groups were formed: women who identified worries as a cause $(n=26,13.5 \%)$ and women who identified other causes $(n=98,51 \%)$.

Table 5 - Significant higher proportions presented by women who identified worries as a cause:

\begin{tabular}{|c|c|c|c|c|c|}
\hline \multicolumn{3}{|c|}{ Obstetric variables } & $\mathrm{X}^{2}$ & $\mathrm{p}$ & $\mathrm{OR}$ \\
\hline $\begin{array}{c}\text { Assisted delivery } \\
(52.6 \%)\end{array}$ & Vaginal (20\%) & 6.079 & $\mathbf{0 . 0 3 0}$ & 4.444 \\
\cline { 1 - 4 } $\begin{array}{c}\text { Assisted delivery } \\
(52.6 \%)\end{array}$ & vs & $\begin{array}{c}\text { Caesarean- } \\
\text { section (22.2\%) }\end{array}$ & 5.357 & $\mathbf{0 . 0 2 1}$ & 3.827 \\
\cline { 3 - 6 } $\begin{array}{c}\text { Breast-feeding } \\
(36.0 \%)\end{array}$ & $\begin{array}{c}\text { Bottle-feeding } \\
(12.9 \%)\end{array}$ & 5.160 & $\mathbf{0 . 0 2 3}$ & .263 \\
\hline
\end{tabular}

When considering the obstetric variables, we can observe (Table 5) that women who had an assisted delivery (forceps and/or vacuum extraction), identified worries as a cause to changes in sleep pattern in a higher proportion than women that had a vaginal 
delivery (OR 4.444, 95\% IC $1.308-15.107$ ) or a caesarean-section (OR 3.827, 95\% IC 1.191 - 12.293). In the same way, women that breast feed their babies also referred to worries as a cause to sleep worse that women that fed their babies with a bottle (OR $3.827,95 \%$ IC 1.191 - 12.293).

Table 6 - Proportions of social and health variables categories presented by women who identified worries as a cause

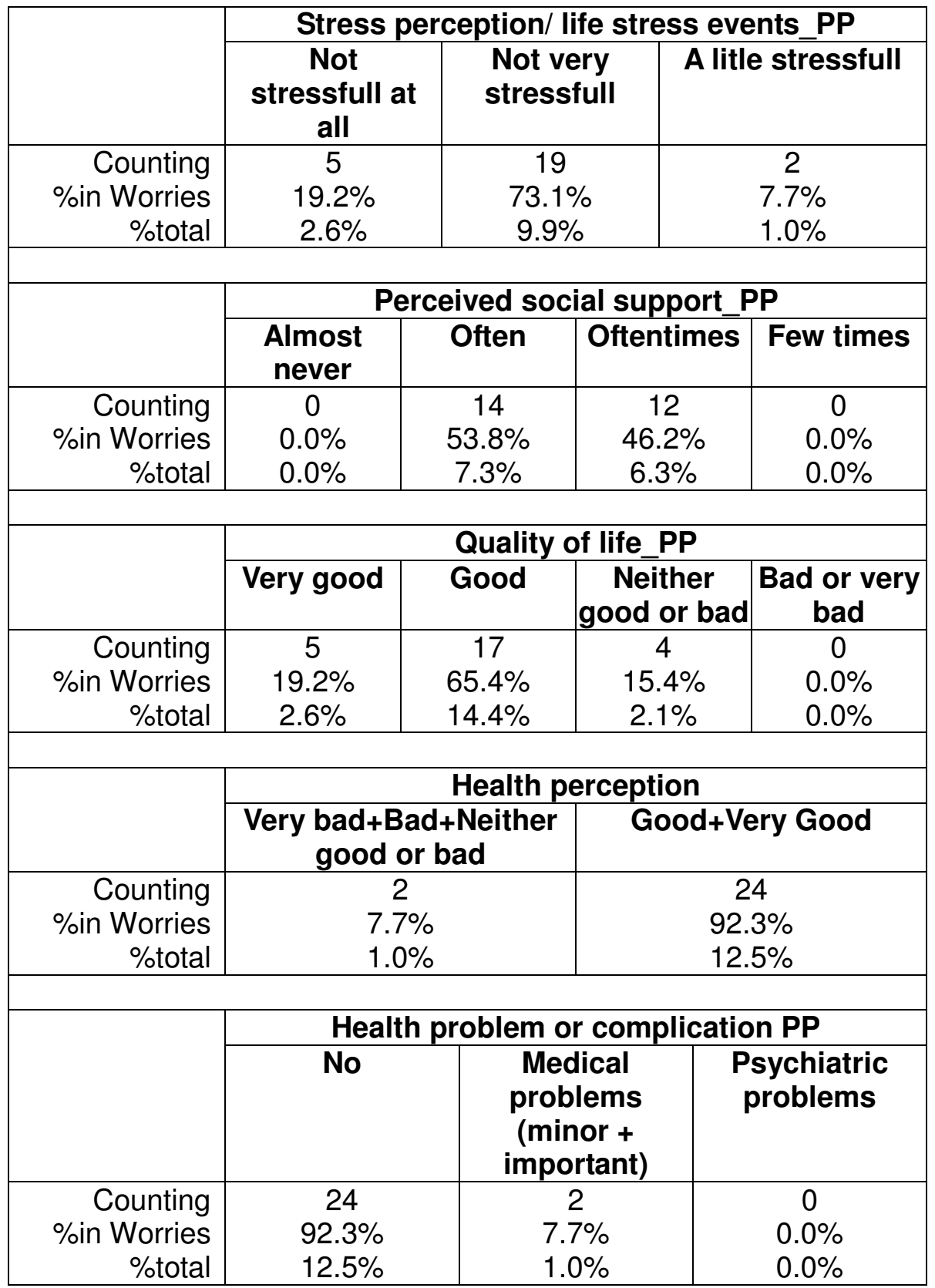

At Table 6 we depict the stress perception and the perceived social support by women at post-partum. It is possible to observe that most of the women $(n=19 ; 77.1 \%)$ from the 
worries group considered their life as not very stressful, 5 (19.2\%), considered life not stressful at all and only $2(7.7 \%)$ considered it a little stressful. Regarding the variable perceived social support, 14 women (53.8\%) referred to receive help often and 12 $(46.2 \%)$ women referred to receive help very often. As for quality of life, most women $(n=17,65.4 \%)$ reported it to be Good. Concerning Health in the past, most of the worries group women considered it to be Good or very Good ( $n=24,92.3 \%)$ and the same number of women from the worries group $(n=24,92.3 \%)$ reported no health problem or complication in the postpartum.

Table 7 - Proportions of sleep variables categories presented by women who identified worries as a cause

\begin{tabular}{|r|c|c|c|}
\cline { 2 - 4 } \multicolumn{1}{c|}{} & \multicolumn{3}{c|}{ Current insomnia } \\
\cline { 2 - 4 } \multicolumn{1}{c|}{} & $\begin{array}{c}\text { Good } \\
\text { Sleepers }\end{array}$ & $\begin{array}{c}\text { Insomnia } \\
\text { symptoms }\end{array}$ & $\begin{array}{c}\text { Insomina } \\
\text { Syndrome }\end{array}$ \\
\hline Counting & 8 & 10 & 8 \\
\%in Worries & $30.8 \%$ & $38.5 \%$ & $30.8 \%$ \\
\%total & $4.2 \%$ & $5.2 \%$ & $4.2 \%$ \\
\hline & \multicolumn{3}{c|}{ Lifetime insomnia } \\
\hline & No & Symptom \\
& \multicolumn{3}{c|}{+ loss } \\
\hline Counting & 18 & 8 \\
\%in Worries & $69.2 \%$ & $30.8 \%$ \\
\%total & $9.4 \%$ & $4.2 \%$ \\
\hline
\end{tabular}

Most of the women $(n=10,38.5 \%)$ referring to worries as a cause change in sleep pattern (Table 7) were included in the Insomnia symptoms group, 8 (30.8\%) were included in the good sleepers group and the same number was included in the Insomnia Syndrome group. Concerning the lifetime history of insomnia, $30.8 \%(n=8)$ of the worries' group also mentioned to have had a period of one month or more where they slept poorly (difficulty falling asleep, waking up many times during the night or waking up too early in the morning and unable to go back to sleep?") and that it interfered a lot with life or activities. 


\section{Table 8 - Proportions of depressive variables categories presented by women who identified worries as a cause}

\begin{tabular}{|c|c|c|}
\hline & \multicolumn{2}{|c|}{$\begin{array}{l}\text { Perception of previous } \\
\text { depressive syndrome }\end{array}$} \\
\hline & No & Yes \\
\hline \multirow{5}{*}{$\begin{array}{r}\text { Counting } \\
\text { \%in worries } \\
\% \text { ototal } \\
\end{array}$} & 17 & 9 \\
\hline & $65.4 \%$ & $34.6 \%$ \\
\hline & $8.9 \%$ & $4.7 \%$ \\
\hline & \multicolumn{2}{|c|}{ PDSS_CUTOFF SCORE } \\
\hline & $<66$ & $>66$ \\
\hline \multirow{5}{*}{$\begin{array}{r}\text { Counting } \\
\text { \%in Worries } \\
\% \text { ototal }\end{array}$} & 16 & 9 \\
\hline & $64.0 \%$ & $36.0 \%$ \\
\hline & $8.8 \%$ & $4.9 \%$ \\
\hline & \multicolumn{2}{|c|}{ BDI-II_CUTOFF SCORE } \\
\hline & $<10$ & $>10$ \\
\hline \multirow{5}{*}{$\begin{array}{r}\text { Counting } \\
\text { \%in Worries } \\
\text { \%total } \\
\end{array}$} & 5 & 19 \\
\hline & $20.8 \%$ & $79.2 \%$ \\
\hline & $2.7 \%$ & $10.3 \%$ \\
\hline & \multicolumn{2}{|c|}{ Major depression_DSMIV } \\
\hline & No & Yes \\
\hline \multirow{5}{*}{$\begin{array}{r}\text { Counting } \\
\text { \%in Worries } \\
\text { \%total }\end{array}$} & 25 & 1 \\
\hline & $96.2 \%$ & $3.8 \%$ \\
\hline & $13.0 \%$ & $0.5 \%$ \\
\hline & \multicolumn{2}{|c|}{ Depressive disorder_ICD1C } \\
\hline & No & Yes \\
\hline Counting & 24 & 2 \\
\hline \%in Worries & $92.3 \%$ & $7.7 \%$ \\
\hline \%total & $12.5 \%$ & $1 \%$ \\
\hline
\end{tabular}

Regarding depression diagnosis, we can observe in the Table 8 that from the group of women who identified worries as a cause, $1(3.8 \%)$ was previously diagnosed with Major Depression according to DSM-IV and 2 (7.7\%) were diagnosed with depression according to ICD-10.

Moreover, $34.6 \%(n=9)$ of women that had the perception of previous depressive syndrome referred to worries as a cause for changes in sleep pattern.

Furthermore, women who identified worries as a cause, also had higher proportions of "having trouble sleeping even when the baby was asleep [(PDSS_Item 1) (28\% vs. 
2.9\%; OR 12.833)], BDI-II scores above the cut-off score (20.8\% vs. $9.2 \%)$ and PDSS35 scores above the cut-off score $(64.0 \%$ vs. $36.0 \%)$.

Table 9 - Worries group vs. Other causes group

(considering the indicated variables)

\begin{tabular}{|l|c|}
\hline Variable & $\mathbf{p}$ \\
\hline Age & 0.959 \\
\hline Educational level & 0.160 \\
\hline Sleep needs & 0.202 \\
\hline Number of depression episodes & 0.607 \\
\hline $\begin{array}{l}\text { PSP } \\
\text { socially prescribed perfectionism }\end{array}$ & 0.733 \\
\hline PAO & \\
\hline self-imposed pressure & 0.407 \\
\hline EMP_Total & \\
\hline PDSS_Total & 0.396 \\
\hline Sleep and eating disturbances & $\mathbf{0 . 0 0 2}$ \\
\hline Anxiety/Insecurity & $<.001$ \\
\hline LAB_EM & $\mathbf{0 . 0 1 1}$ \\
\hline Mental confusion/MNT & 0.185 \\
\hline Loss of Self/LOS & $\mathbf{0 . 0 1 5}$ \\
\hline Guilty/Shame/GLT & $\mathbf{0 . 0 0 5}$ \\
\hline Suicidal Ideation & $\mathbf{0 . 0 2 6}$ \\
\hline Derealization and Failure & 0.252 \\
\hline Concentration difficulties and & $\mathbf{0 . 0 4 0}$ \\
\hline emotional labitlity & $\mathbf{0 . 0 3 0}$ \\
\hline Suicidal Ideation and Stigma & \\
\hline Sleeping dificulties & 0.060 \\
\hline POMS_TA & $<.001$ \\
\hline POMS_D & 0.365 \\
\hline POMS_H & $\mathbf{0 . 0 3}$ \\
\hline POMS_VA & 0.068 \\
\hline POMS_FI & 0.130 \\
\hline POMS_CB & $\mathbf{0 . 0 1 9}$ \\
\hline BDI_SOMA_ANX & 0.185 \\
\hline BDI_COG-AF & $<.001$ \\
\hline BDITOTAL & 0.074 \\
\hline NoIns_ep & $<.001$ \\
\hline Life_Quality_PP & $\mathbf{0 . 0 3 0}$ \\
\hline Temp_Total & 0.811 \\
\hline & 0.062 \\
\hline
\end{tabular}


Table 10 - Medians of the Worries group vs. Other causes group (Significant diferences)

\begin{tabular}{|c|c|}
\hline & Md ( \pm interquatile range) \\
\hline PDSS-35_Total & $73 \pm 57$ vs. $53 \pm 37$ \\
\hline Sleeping/eating disturbances & $13.5 \pm 6.75$ vs. $9 \pm 8.50$ \\
\hline Anxiety/insecurity/ANX) & $14 \pm 10.25$ vs. $10.50 \pm 8.25$ \\
\hline Mental confusion/MNT & $10.5 \pm 7.5$ vs. $9 \pm 7.25$ \\
\hline Loss of Self/LOS & $11.0 \pm 10.25$ vs. $9.50 \pm 4.25$ \\
\hline Guilty/Shame/GLT & $7.5 \pm 7.5$ vs. $6.00 \pm 5.00$ \\
\hline Derealization and failure & $17 \pm 14$ vs. $9.50 \pm 9.25$ \\
\hline $\begin{array}{l}\text { Concentration difficulties and } \\
\text { emotional labitlity }\end{array}$ & $13 \pm 11$ vs. $12.50 \pm 7.00$ \\
\hline Suicidal Ideation and Stigma & $6.5 \pm 2.75$ vs. $5.00 \pm .00$ \\
\hline Sleeping dificulties & $8.5 \pm 6.5$ vs. $6.00 \pm 7.50$ \\
\hline POMS_Depression & $8.0 \pm 3.25$ vs. $6.00 \pm 7.50$ \\
\hline POMS_Fatigue Inertia & $6.0 \pm 3.75$ vs. $8.50 \pm 3.50$ \\
\hline BDI-II_Total & $7.0 \pm 3.25$ vs. $8.50 \pm 3.50$ \\
\hline BDI-II_Somatic Anxiety & $6.5 \pm 9.75$ vs. $6.50 \pm 9.00$ \\
\hline
\end{tabular}

We observed in Tables 9 and 10 that total PDSS, Sleeping/eating disturbances, Anxiety/insecurity, Mental confusion, Loss of self and Guilty/shame, Derealization and failure, Concentration difficulties and Emotional lability, Suicidal Ideation and Stigma, Sleeping dificulties variables showed significantly higher medians in the group that considered worries as the cause for changes in sleep pattern. The two groups (worries vs. other causes) did not significantly differ in infant temperament, life quality in the postpartum, sleep needs, educational levels, age, BDI cognitive-affective, several POMS dimensions (Confusion, Vigor-activity, Hostility, Tension-anxiety), Suicidal ideation/stigma, Suicidal ideation, Emotional lability, PSP and PAO. 


\section{DISCUSSION}

During pregnancy and postpartum, as a result of anatomical, physiological and hormonal changes typical of pregnancy, most women suffer significant changes in sleep, starting in early pregnancy and tend to increase in frequency and duration during pregnancy ${ }^{39}$. Moreover, many women fail to recognize that insomnia, lack of energy and changes in appetite / weight, usual in pregnancy and postpartum, are depressive symptoms, delaying seeking help ${ }^{40,41}$.

Studies regarding insomnia at postpartum are scarce and the literature focuses on sleep quality, latency, duration and efficiency changes and not on the occurrence of sleep disorders, as insomnia. Therefore it becomes relevant to better understand insomnia as well as the causes perceived by women to suffer changes in their sleep pattern during the postpartum period so that health professionals can identify the most vulnerable women before delivery and closer monitor and take preventive strategies.

In this study we observed that more than half of the interviewed women (106, 57.7\%) reported a change in their sleep pattern. $64.8 \%$ of those identified some causes, $32.3 \%$ of which mentioned the feeding and/or baby care and older children care and $29.5 \%$ mentioned worries (baby and life problems related).

The notion that, in general population, worries have a disruptive effect in sleep patterns is not new, but as far as we know this is the first time worries as a cause for changes in sleep pattern is studied in the postpartum population. A recent study by Dregan et al. ${ }^{42}$ approached this question in the general population in a big sample representative of the reality in UK $(n=7403)$. In that study, $40.4 \%$ of the participants reported a sleep problem in the week before. In that study from Dregan and collaborators ${ }^{42}$, among the participants that identified a specific reason for their sleep problems, worry stands out with $38 \%$ followed by illness with $20 \%$. In our specific population this value is not so different, with $29.5 \%$ of women referring to it.

In our study, $30.7 \%$ of women report at least one episode of insomnia in life. This estimate is slightly higher than the monthly prevalence of $27.4 \%$ in a longitudinal study over 20 years $^{22}$. When considering the postpartum period, there are few studies evaluating insomnia. Durkheim et al. ${ }^{43}$ evaluated the prevalence of sleep problems in the 7th week postpartum through the Pittsburgh Sleep Quality Index (PSQI ${ }^{44}$ ) and found that nearly $60 \%$ of the postpartum women experienced poor global sleep quality. 
In our sample, prevalence of sleep problems (Insomina Symptoms + Insomnia Syndrome groups $=55.7 \%$ ) at the 3rd month postpartum (we can only compare this estimate: our participants answered how was your sleep last month, between the 2nd and 3rd month postpartum / around 8 weeks postpartum) was also high. Furthermore, the group of women mentioning worries as a cause for changes in sleep pattern were mainly included in the Insomnia Symptoms Group $(n=10,38.5 \%)$ if considering current insomnia status and in the No lifetime history of insomnia group $(n=18,69.2 \%)$. Those women had also significantly higher number of insomnia episodes comparing to the other causes group.

Taking into account the obstetric variables, we observed a positive relation between the worries group and assisted delivery vs vaginal or caesarean-section. When analyzing the type of baby-feeding, women breastfeeding reported worries in higher levels than women bottle-feeding.

Contrary to our expectations, no significant difference was observed between the groups when considering the perceived stress postpartum, perceived social support, quality of life, past health or health problems at the postpartum.

Despite difficult infant temperament has been cited as a considerable stressor for the mother in the postpartum period ${ }^{45}$, we found in our study that there was no significant difference between the worries group and the other causes group when considering this variable.

It is known that personality traits, such as perfectionism, play important and differential roles in depressive symptomatology in non-childbearing populations ${ }^{46}$ and also in the perinatal period ${ }^{47}$. Given this, we wanted to evaluate whether the worries group could have different perfectionism levels when comparing to the other causes group, but when applying the Multidimensional Perfectionism Scale we found no differences between groups.

Depression and Insomnia are comorbid and interrelated conditions ${ }^{48-50}$, and insomnia is often a precursor of, as well as a negative prognostic factor for depression. The choice of the period of three months after delivery to the hold this study was related with the fact the risk of developing a depressive episode is three times higher than in the first five weeks postpartum ${ }^{51}$ and that in the first three months after birth there is a greater likelihood of developing a depressive episode ${ }^{52}$. Futhermore, Goyal et al. ${ }^{53}$ confirm the association between sleep disruption and depressive symptoms at 3 months postpartum. 
In our study, depressive symptoms were assessed with the BDI-II and PDSS and the Profile of Mood States (POMS) was used to evaluate the negative and positive affect. Women referring to worries as the cause for changes in sleep pattern had higher scores in two dimensions of POMS: Depression and Fatigue-inertia. Furthermore, they also had higher scores in BDI-II total, specifically at the somatic-anxiety dimension, which means that these women had higher levels of crying, agitation, changes in appetite, sleep disturbances, irritability, tiredness or fatigue, loss of energy, difficulty concentrating, indecision and decreased libido.

The PDSS evaluates the presence and severity of symptoms of postpartum depression and functions as screening of the disease by identifying women who have a high probability to meet the diagnostic criteria for depression. We have found that PDSS total scores and most of their symptomatic dimensions (sleep and eating disturbances, anxiety/insecurity, mental confusion, loss of self, guilty/shame, derealization-failure, concentration difficulties and emotional lability as well as sleeping difficulties) were significantly higher in group of women considering worries as the cause not to sleep vs. other causes, suggesting that these women are in higher risk of developing depressive episodes or recurrence of depression.

In conclusion, it is important to underline that although a significant number of women complain about sleep disturbances at postpartum, that can be unappreciated by both health professionals and mothers, mainly because they believe the sleep disruption is "normal", particularly related to baby needs, and have expectations that sleep will, eventually, regularize in the first year postpartum. As we observed in this study, women that point to worries as their cause not to sleep in the same way as before childbirth, can be at risk of developing postpartum depression since they had higher scores in the depression related scales (POMS, BDI-II and PDSS).

Although there are no studies concerning worries as a cause of sleep difficulties in the postpartum, there are many studies about the cognitive models of insomnia in the general population that can help us better understand the role of worries in the insomnia process. Those models describe that many people with insomnia report that mental events, such as intrusive thoughts or repetitive negative thoughts, prevent them from sleeping. Such cognitive activity can include uncontrollable worry, depressive rumination, intrusive thoughts and an overly active or 'racing' mind. Furthermore, 
because 'normal' sleep is a relatively automatic process that cannot be forced by will, it is vulnerable to disruption by patients consciously thinking about sleep and by direct attempts to control the process. Harvey et al. ${ }^{54}$ describes a model for maintenance of insomnia, with an entry point at excessive negatively toned cognitive activity about getting enough sleep and about the impact the sleep disturbance is having on health and/or daytime functioning. These excessive worries and ruminations trigger autonomic arousal and emotional distress, which results in the activation of the sympathetic nervous system activation and plugs the individual into an anxious state. Having these models into account, we can understand that it becomes even more clear that special attention should be paid to women referring to worries as a cause to sleep disturbance in postpartum period. 


\section{ACKNOWLEDGMENTS}

I would first like to thank my thesis advisor Doctor Ana Telma Pereira for the opportunity to work with her in this area and also for all the help she provided during this thesis elaboration.

I would also like to thank to the Director of the Medical Psychology Institute of the Faculty of Medicine (University of Coimbra), Professor António Macedo, for allowing me to develop this work at the Department of Psychological Medicine.

I thank to all mothers who participated in this study.

Finally, I must express my very profound gratitude to my family for providing me with unfailing support and continuous encouragement throughout my years of study and through the process of researching and writing this thesis. This accomplishment would not have been possible without them. Thank you. 


\section{REFERENCES}

1. Pereira AT, Bos S, Marques M, Maia BR, Soares MJ, Valente J, et al. The Portuguese version of the postpartum depression screening scale. J Psychosom Obstet Gynaecol [Internet]. 2010;31(2):90-100. Available from:

http://www.ncbi.nlm.nih.gov/pubmed/20443658

2. Morin CM, LeBlanc M, Daley M, Gregoire JP, Mérette C. Epidemiology of insomnia: Prevalence, self-help treatments, consultations, and determinants of help-seeking behaviors. Sleep Med. 2006;7(2):123-30.

3. Aasm. International Classification of Sleep Disorders: Diagnostic and Coding Manual. (ICSD-2) [Internet]. Diagnostic Coding Manual. 2005. xviii, 297 p. Available from: http://www.esst.org/adds/ICSD.pdf

4. World Health Organization. The ICD-10 Classification of Mental and Behavioural Disorders. Int Classif. 1992;10:1-267.

5. APA. Diagnostic and statistical manual of mental disorders (4th ed.). Diagnostic and statistical manual of mental disorders (4th ed.) 1994 p. 69-81.

6. Foley DJ, Monjan A, Brown SL, Simonsick EM, Wallace RB, Blazer DG. Sleep complaints among elderly persons: an epidemiologic study of three communities. Sleep. $1995 ; 18(6): 425-32$.

7. Kalogjera-Sackellares D, Cartwright RD. Comparison of MMPI profiles in medically and psychologically based insomnias. Psychiatry Res. 1997;70(1):49-56.

8. LeBlanc M, Beaulieu-Bonneau S, Mérette C, Savard J, Ivers H, Morin CM. Psychological and health related quality of life factors associated with insomnia in a population based sample. J Psychosom Res. 2007;63:157-66.

9. Lindberg E, Janson C, Gislason T, Björnsson E, Hetta J, Boman G. Sleep disturbances in a young adult population: can gender differences be explained by differences in psychological status? Sleep [Internet]. 1997;20(6):381-7. Available from: http://www.ncbi.nlm.nih.gov/pubmed/9302720

10. Shaver JL, Paulsen VM. Sleep, psychological distress, and somatic symptoms in perimenopausal women. Fam Pract Res J. 1993;13(4):373-84.

11. Taylor DJ, Lichstein KL, Durrence HH, Reidel BW, Bush AJ. Epidemiology of insomnia, depression, and anxiety. Sleep. 2005;28(11):1457-64.

12. Bonnet MH, Arand DL. Hyperarousal and insomnia: State of the science. Vol. 14, Sleep Medicine Reviews. 2010. p. 9-15.

13. Edinger JD, Stout AL, Hoelscher TJ. Cluster analysis of insomniacs' MMPI profiles: Relation of subtypes to sleep history and treatment outcome. Psychosom Med. 1988;50:77-87.

14. Ford DE, Kamerow DB. Epidemiologic study of sleep disturbances and psychiatric disorders. An opportunity for prevention? JAMA [Internet]. 1989;262(11):1479-84. Available from: http://www.ncbi.nlm.nih.gov/pubmed/2769898

15. Hauri P, Fisher J. Persistent psychophysiologic (learned) insomnia. Sleep. 1986;9(November 1985):38-53. 
16. Jansson M, Linton SJ. Psychological mechanisms in the maintenance of insomnia: Arousal, distress, and sleep-related beliefs. Behav Res Ther. 2007;45(3):511-21.

17. Morin CM. Insomnia: Psychological assessment and management. [Internet]. Treatment manuals for practitioners. Guilford Press, New York, NY; 1993. 238-xvii, 238. Available from: http://search.proquest.com/docview/618402446?accountid=17225

18. Morin CM, Ware JC. Sleep and psychopathology. Appl Prev Psychol [Internet]. 1996;5(4):211-24. Available from: ISI:A1996VP24200002

19. Ohayon MM, Caulet M, Lemoine P. Comorbidity of mental and insomnia disorders in the general population. Compr Psychiatry. 1998;39(4):185-97.

20. Germain A, Thase ME. Sleep Dysregulation and Related Regulatory Models. In: Risk Factors in Depression. Elsevier Inc.; 2008. p. 91-117.

21. Riemann D, Voderholzer U. Primary insomnia: A risk factor to develop depression? J Affect Disord. 2003;76(1-3):255-9.

22. Buysse DJ, Angst J, Gamma A, Ajdacic V, Eich D, Rössler W. Prevalence, course, and comorbidity of insomnia and depression in young adults. Sleep [Internet]. 2008;31(4):473-80. Available from: http://www.pubmedcentral.nih.gov/articlerender.fcgi?artid=2279748\&tool=pmcentrez \&rendertype=abstract

23. O'Hara MW, Wisner KL. Perinatal mental illness: Definition, description and aetiology. Best Pract Res Clin Obstet Gynaecol. 2014;28(1):3-12.

24. Riecher-Rössler A. Prospects for the classification of mental disorders in women. Eur Psychiatry [Internet]. 2010;25(4):189-96. Available from:

http://www.sciencedirect.com/science/article/pii/S0924933809000510

25. Foundation NS. Women and Sleep poll [Internet]. 2007. Available from: http://www.sleepfoundation.org/publications

26. Lee KA, Zaffke ME, McEnany G. Parity and sleep patterns during and after pregnancy. Obstet Gynecol. 2000;95(1):14-8.

27. Stremler R, Wolfson A. The postpartum period. In: Principles and Practice of Sleep Medicine 5th ed. 2011. p. 1587-90.

28. Marques et al.Is insomnia in late pregnancy a risk factor for postpartum depression2010.

29. Azevedo MHP, Valente J, Macedo A, Dourado A, Coelho I, Pato M, et al. Versão Portuguesa da "Entrevista Diagnóstica para Estudos Genéticos." Psiquiatr Clínica. 1993;14:213-7.

30. Soares MJ, Dourado A, Macedo A, Valente J, Coelho I, Azevedo MH. Estudo de Fidelidade da Lista de Critérios Operacionais para Doenças Psicóticas. Psiquiatria Clínica 1997;18:11-24.

31. Beck CT, Gable RK. Postpartum Depression Screening Scale Manual. Western Psychological Services, Los Angeles.; 2002.

32. Beck AT, Steer RA, Brown GK. Manual for the Beck depression inventory-II. San Antonio, TX Psychol Corp. 1996;1-82.

33. Coelho R, Martins A, Barros H. Clinical profiles relating gender and depressive symptoms 
among adolescents ascertained by the Beck Depression Inventory II. Eur Psychiatry [Internet]. 2002;17(4):222-6. Available from: http://www.sciencedirect.com/science/article/pii/S0924933802006636

34. Carvalho Bos S, Pereira AT, Marques M, Maia B, Soares MJ, Valente J, et al. The BDI-II factor structure in pregnancy and postpartum: Two or three factors? Eur Psychiatry. 2009;24(5):334-40.

35. Azevedo MH, Silva CF, Dias MR. O "Perfil de Estados de Humor": Adaptação à População Portuguesa. Psiquiatr Clínica. 1991;12:187-93.

36. McNair DM, Lorr M, Droppleman LF. Edits manual for the profile of mood states. Educational and Industrial Testing Service, San Diego.; 1971.

37. Macedo A, Marques M, Bos S, Maia BR, Pereira T, Soares MJ, et al. Mother's personality and infant temperament. Infant Behav Dev. 2011;34(4):552-68.

38. Soares M, Gomes A, Macedo A, Santos V, Azevedo MH. Escala Multidimensional de Perfeccionismo: Adaptação à População Portuguesa. Rev Port Psicossomática. 2003;5:46-55.

39. Balserak BI, Lee K. Sleep Disturbances and Sleep-Related Disorders in Pregnancy. In: Principles and Practice of Sleep Medicine: Fifth Edition. 2010. p. 1572-86.

40. Buist A. Perinatal depression. Assessment and management. Aust Fam Physician. 2006;35(9):670-3.

41. Pereira AT, Marques M, Soares MJ, Maia BR, Bos S, Valente J, et al. Profile of depressive symptoms in women in the perinatal and outside the perinatal period: Similar or not? J Affect Disord. 2014;166:71-8.

42. Dregan A, Lallukka T, Armstrong D. Potential pathways from biopsychosocial risk factors to sleep loss due to worry: a population-based investigation. J Public Ment Health [Internet]. 2013;12(1):43-50. Available from: http://www.emeraldinsight.com/doi/abs/10.1108/17465721311304230

43. Dørheim SK, Bondevik GT, Eberhard-gran M, Bjorvatn B. Sleep and Depression in Postpartum Women : A Population-Based Study. 2006;

44. Buysse, D.J., Reynolds, C.F., Monk, T.H., Berman, S.R., Kupfer, D.J. (1989). The Pittsburgh Sleep Quality Index: a new instrument for psychiatric practice and research. Psychiatry Research, 28, 193-213.

45. Cutrona CE, Troutman BR. Social Support, Infant Temperament, and Parenting SelfEfficacy: A Mediational Model of Postpartum Depression. Source Child Dev [Internet]. 1986;5718273(6):1507-18. Available from: http://www.jstor.org/stable/1130428\nhttp://www.jstor.org/page/

46. Sherry SB, Law A, Hewitt PL, Flett GL, Besser A. Social support as a mediator of the relationship between perfectionism and depression: A preliminary test of the social disconnection model. Pers Individ Dif. 2008;45(5):339-44.

47. Maia BR, Pereira AT, Marques M, Bos S, Soares MJ, Valente J, et al. The role of perfectionism in postpartum depression and symptomatology. Arch Womens Ment Health. 2012;15(6):459-68.

48. Lichstein KL, Rosenthal TL. Insomniacs ' Perceptions of Cognitive Versus Somatic Determinants of Sleep Disturbance. J Abnorm Psychol. 1980;89(1):105-7. 
49. Espie CA, Brooks DN, Lindsay WR. An evaluation of tailored psychological treatment of insomnia. J Behav Ther Exp Psychiatry. 1989;20(2):143-53.

50. Harvey AG. Pre-sleep cognitive activity: a comparison of sleep-onset insomniacs and good sleepers. Br J Clin Psychol. 2000;39 ( Pt 3):275-86.

51. Cox JL, Murray D, Chapman G. A controlled study of the onset, duration and prevalence of postnatal depression. Br J Psychiatry. 1993;163(JULY):27-31.

52. Cooper PJ, Campbell EA, Day A, Kennerley AD, Bond A. Non-psychotic psychiatric disorder after childbirth. A prospective study of prevalence, incidence, course and nature. Br J Psychiatry. 1988;152(JUN.):799-806.

53. Goyal D, Gay C, Lee K. Fragmented maternal sleep is more strongly correlated with depressive symptoms than infant temperament at three months postpartum. Arch Womens Ment Health. 2009;12(4):229-37.

54. Harvey AG. A cognitive model of insomnia. Behav Res Ther. 2002;40(8):869-93. 